in vivo $35: 1461-1466(2021)$

doi:10.21873/invivo.12398

\title{
Differential Expression of BDNF and BIM in Streptozotocin-induced Diabetic Rat Retina After Fluoxetine Injection
}

\author{
SEONG TAECK KIM ${ }^{1}$, YOON YOUNG CHUNG ${ }^{2}$, HYO-IN HWANG ${ }^{2}$, \\ HYE-KYOUNG SHIN ${ }^{2}$, RANJU $\mathrm{CHOI}^{3}$ and YONG HYUN JUN ${ }^{2}$ \\ ${ }^{1}$ Department of Ophthalmology, Chosun University Hospital, Gwangju, Republic of Korea; \\ ${ }^{2}$ Department of Anatomy, School of Medicine, Chosun University, Gwangju, Republic of Korea; \\ ${ }^{3}$ School of Medicine, Chosun University, Gwangju, Republic of Korea
}

\begin{abstract}
Background: Chronic diabetic retinopathy (DR) is a diabetic complication that causes blindness. Brainderived neurotrophic factor (BDNF) expression is induced by fluoxetine. We observed the effects of fluoxetine on a streptozotocin (STZ)-induced diabetic rat model in this study. Materials and Methods: Rats were divided into three groups: Control, diabetic (65 mg/kg STZ injection), and diabetic with fluoxetine injection (20 mg/kg/week, six times). Western blotting was performed using anti-BDNF and anti-hexaribonucleotide-binding protein-3. Expression of BCL2 apoptosis regulator-like protein 11 (BIM) was analysed using a reverse transcription-polymerase chain reaction. Results: $B D N F$ levels were significantly higher in the diabetic group treated with fluoxetine than in the untreated diabetic group. BIM expression was higher in the diabetic group than in the control group. BIM gene expression was lower in the fluoxetine-treated diabetic group than in the untreated diabetic group. Conclusion: Fluoxetine had an anti-apoptotic effect with up-regulation of BDNF expression in the retina of rats with $S T Z$-induced diabetes.
\end{abstract}

Diabetic retinopathy (DR) is a complication of diabetes that causes blindness (1). Important mechanisms of blindness are macular edema and alteration of neovascularisation $(2,3)$. Vascular endothelial growth factor (VEGF) is the most effective mediator of DR progression (4). Anti-VEGF effects

This article is freely accessible online.

Correspondence to: Yong Hyun Jun, Department of Anatomy, School of Medicine, Chosun University, 375 Seosuk-dong, DongGu, Gwangju 501-759, Republic of Korea. Tel: +82 0622306131, Fax:+82 0622341474, e-mail: jyh1483@chosun.ac.kr

Key Words: BDNF, BIM, diabetic, fluoxetine, retina. are associated with the regression of retinal neovascularisation (5) and anti-VEGF treatment is the most effective approach for DR therapy. However, some patients show poor response to this treatment (6). Thus, comprehension of the pathogenesis of DR is critical. Although DR is traditionally known as a vascular disease, some studies have shown that neuronal pathological changes occur in the retina, including physiological and structural alterations $(7,8)$.

Brain-derived neurotrophic factor (BDNF) is a neuroprotective growth factor that affects neuronal cell proliferation and survival (9). BDNF binds to tropomyosin receptor kinase $B$ (TRKB), which leads to nerve cell survival, repair, and development through the neurotrophic signalling pathway (10). BDNF has also been observed in retinal neuronal cells. BDNF is expressed in retinal ganglion cells (RGCs) and was found to play an important role in their survival in rats with streptozotocin (STZ)-induced diabetes (11). Cusato et al. reported that BDNF prevented cell death in the inner nuclear layer of the retina (12). Uzel et al. showed that BDNF is a good marker for the early diagnosis of DR (13).

In a previous study, BDNF expression was induced by fluoxetine, a selective inhibitor of serotonin reuptake, to treat major depression (14). In this study, we analysed the expression of BDNF and BCL2 apoptosis regulator-like protein 11 (BIM) after fluoxetine injection in the STZinduced diabetes rat model to investigate the effect of fluoxetine on BDNF signalling.

\section{Materials and Methods}

Rat model of DR. All animal studies were approved by the Chosun University Institutional Animal Care and Use Committee (approval number: CIACUC2019-A0049). Male Sprague-Dawley rats (5-6 weeks old) were supplied by a certified breeder (Damul Laboratory Animals, Republic of Korea). The animal experimental design is illustrated through the schematic diagram shown in Figure 1. The 


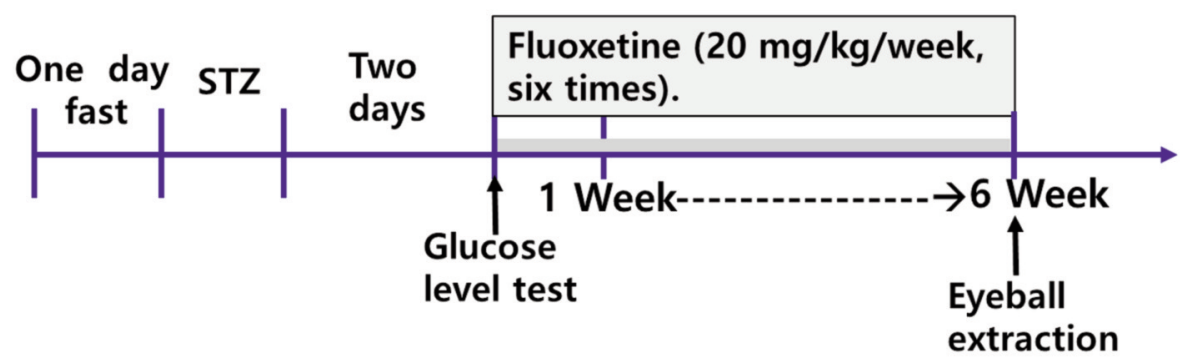

Figure 1. Timetable for the experimental procedures. Blood glucose levels were measured using the tail vein. A high glucose level (>250 mg/dl) was defined as diabetes mellitus (DM).
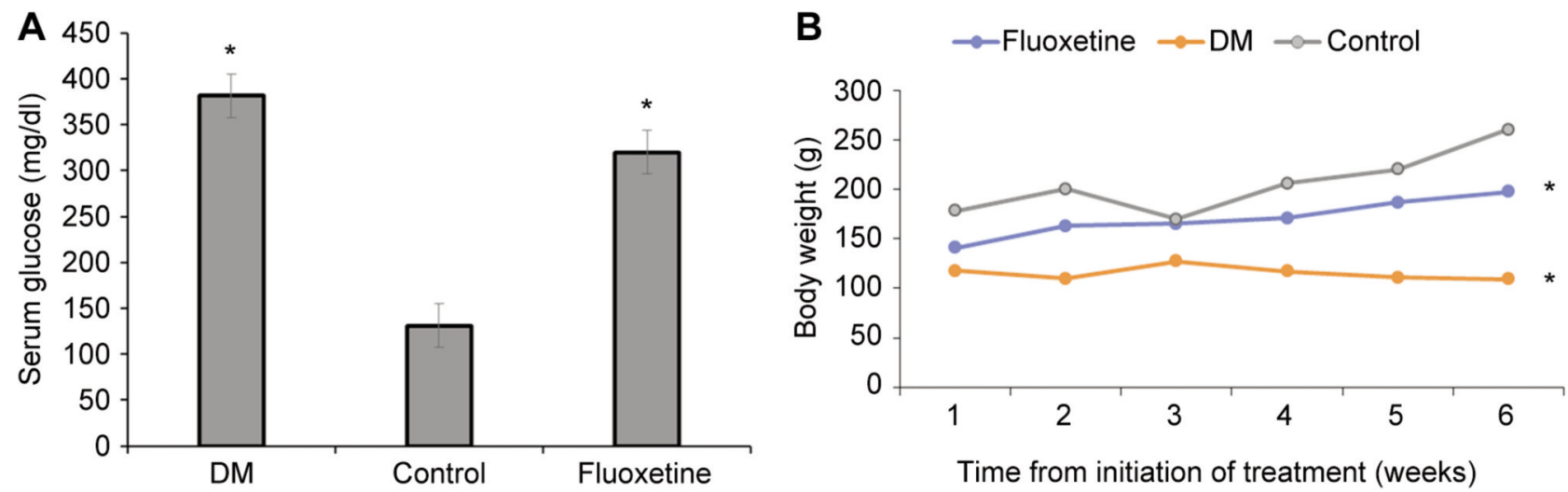

Figure 2. Analysis of serum glucose (A) and body weight (B) in rats of control, diabetes mellitus (DM) and fluoxetine-treated DM groups. The data are expressed as the mean \pm standard error of the mean. *Significantly different from the control at $p<0.05$.

rats were divided into three groups: Control $(n=7)$, diabetic $(n=7)$, and diabetic with fluoxetine injection $(\mathrm{n}=9,20 \mathrm{mg} / \mathrm{kg} / \mathrm{week}$, six times). After one day of fasting, STZ $(65 \mathrm{mg} / \mathrm{kg}$, in $10 \mathrm{mM}$ citrate buffer, pH 4.5; Sigma-Aldrich, St. Louis, MO, USA) was injected intraperitoneally into the rats in the diabetic groups. Two days later, blood glucose levels were measured using the tail vein. A high glucose level (>250 mg/dl) was defined as diabetes.

Western blot analysis. After 6 weeks, all Sprague-Dawley rats $(\mathrm{n}=23)$ were anaesthetised using sevoflurane inhalation $(1.0-2.0 \%$, end-tidal concentration) and the eyeballs were extracted under anaesthesia. Retinas were isolated from each eye. Retinal tissues were lysed using $0.1 \%$ Triton X-100 extraction buffer. Protein quantification in tissue lysates was performed using a bicinchoninic acid protein assay. After protein quantification, sodium dodecyl sulphate gel electrophoresis was performed using equal volumes of protein. Proteins were transferred to nitrocellulose membranes (GE Healthcare, Piscataway, NJ, USA). The membrane was then washed with primary antibodies against $\beta$-actin (1:1,000; Santa Cruz, CA, USA), and rabbit anti-BDNF (1:1000; Abcam, Cambridge, UK).

Reverse transcription-quantitative polymerase chain reaction (RT$P C R$ ) analysis. The expression levels of BCL2-interacting mediator of cell death (Bim) were analysed using qPCR. Total RNA was extracted from the retinas of rats using Triazol. The synthesis of cDNA was performed using ReverTra Ace ${ }^{\circledR}$ qPCR RT Kit (Toyobo Corporation,
Osaka, Japan). The glyceraldehyde-3-phosphate dehydrogenase (Gapdh) gene was used as an internal control. The following primers were used: Gapdh forward: 5'-CCATCAACGACCCCTTCATT-3', and reverse: 5'-CACGACATACTCAGCACCAGC-3' (Gene ID: AF106860.2); Bim forward: 5'-AGATACGGATCGCACAGGAG-3', and reverse: 5'-ACC AGA CGG AAG ATG AAT CG-3' (Gene ID: NM_171988.2). The reaction mixture was as follows: One cycle for 1 min at $95^{\circ} \mathrm{C}, 45$ cycles of $5 \mathrm{~s}$ at $95^{\circ} \mathrm{C}$, and $5 \mathrm{~s}$ at $58^{\circ} \mathrm{C}$. Data were

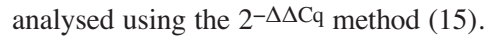

Statistical analysis. Differences between the control, diabetic, and injection groups were evaluated using Kruskal-Wallis one-way analysis of variance. To examine the mean difference among groups, the Mann-Whitney test with Bonferroni adjustment was performed. All data were analysed using the Statistical Package for Social Sciences, Information Analysis Systems (IBM, Armonk, NY, USA). All data are expressed as the mean \pm standard error of the mean. $p$ Values of less than 0.05 were considered statistically significant.

\section{Results}

Bodyweights were checked weekly after fluoxetine administration. The bodyweights of rats in the diabetic group were significantly lower than those of rats in the control group (Figure 2). The bodyweights of rats in the fluoxetine- 


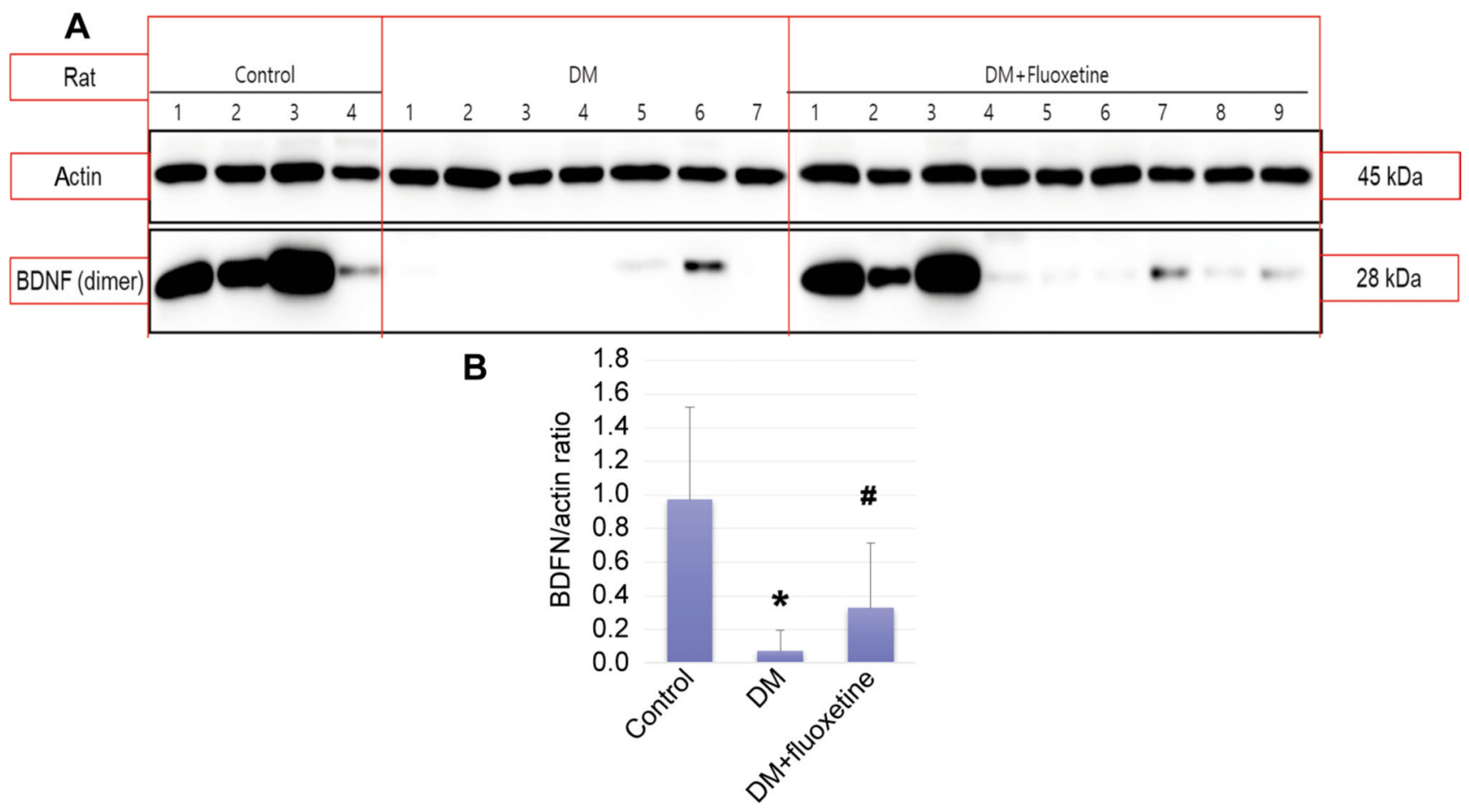

Figure 3. Representative photographs (A) and quantification (B) of brain-derived neurotrophic factor (BDNF) expression on western blot in rats of control, diabetic (DM), and fluoxetine-treated DM groups. A: BDNF levels were significantly increased in the fluoxetine-treated group compared to that in the diabetic group. B: The results were expressed as a ratio compared to actin. The data are expressed as mean and standard error values. Significantly different at $p<0.05$ compared with $*$ control and ${ }^{\#} D M$.

treated diabetic group were significantly higher than those of rats in the diabetic group but was not significantly different from that of the control group. The mean blood glucose levels of the diabetic and the fluoxetine-treated diabetic groups were significantly higher than that of the control group (Figure 2).

Western blot analysis revealed that the mean BDNF level was significantly increased in the fluoxetine-treated group compared to that in the diabetic group (Figures 3 and 4). The gene-expression level of Bim in the diabetic group was higher than that in the control group. However, its gene expression was lower in the fluoxetine-treated group than in the diabetic group (Figure 4).

\section{Discussion}

STZ is an antibiotic that has a side-effect related to pancreatic $\beta$-cell destruction (16). This characteristic allows STZ to be widely used to produce an animal diabetes model (17-19). We defined the diabetic group with tail vein glucose levels following a previous study $(20,21)$.

BDNF expression levels in the diabetic group were lower than those in the control group. Some studies have shown that both protein and mRNA levels of BDNF were lower in patients with diabetes $(22,23)$. In a previous study, BDNF

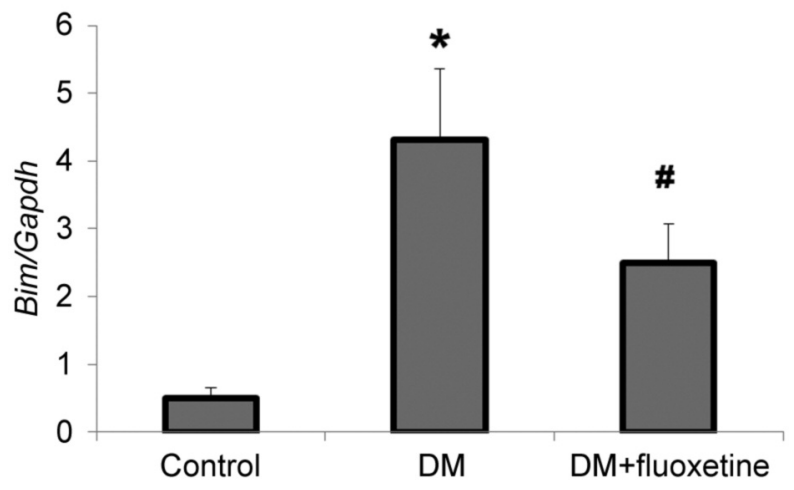

Figure 4. The $m R N A$ expression of BCL2 apoptosis regulator-like protein 11 (Bim) in retinas of normal, diabetes mellitus (DM) and fluoxetinetreated DM rats. The amounts of BIM mRNA expression were normalized to that of the internal control, glyceraldehyde 3-phosphate dehydrogenase. The data are expressed as mean and standard error values. Significantly different at: $p<0.05$ compared with * control and ${ }^{\#} D M$.

levels in patients with non-proliferative DR were reduced in serum and aqueous humour (24). This finding was similar to that of another study on BDNF levels in diabetic patients with retinopathy (25). This suggests that the reduction in 
serum BDNF levels is related to the development of DR (26). Currently, DR is considered a neurovascular disease (27). The early progression of diabetes compromises retinal ganglion and glial cells (28). One study showed that BDNF suppressed apoptosis of RGCs in a glaucoma model (29). In diabetic conditions, BDNF causes phosphorylation of TRKB and stimulates the activation of extracellular-regulated kinase to play a neuroprotective role in the retina (30).

In our study, fluoxetine induced BDNF expression in rats with diabetes. Fluoxetine is a small molecule that mimics neurotrophic signalling (31). One study showed that fluoxetine has a protective effect on retinal epithelial cells (32). Other studies have shown that fluoxetine promotes the recovery of synaptic proteins in the visual cortex $(33,34)$. Several studies have shown that fluoxetine improves BDNF expression and concentration (35-37). Some studies have shown that BDNF expression induced by fluoxetine is associated with BDNF-TRKB signalling $(38,39)$.

We found that Bim expression was lower in the diabetic group than in the control group. Expression was restored in the diabetic group with fluoxetine injection. BIM is a wellknown mediator of cell death and apoptosis, particularly in neuronal cells $(40,41)$. In the inner retina, where RGCs exist, proapoptotic molecules such as BIM and active caspase-8 are increased in patients with diabetes (42). Under high glucose conditions, BIM promotes the apoptosis of pericytes in the retina (43). After injection of fluoxetine in the diabetic group, BDNF expression was induced, and Bim expression was reduced. Some studies have shown that BDNF has a neuroprotective effect by regulating BIM expression $(44,45)$. Li et al. reported that the down-regulation of BIM was related to activation of TRKB in neuroblastoma cells (46). Regarding fluoxetineregulated BDNF with TRKB signalling $(47,48)$, fluoxetine injection was associated with the down-regulation of BIM by TRKB signalling.

In conclusion, fluoxetine appeared to have an antiapoptotic effect with up-regulation of BDNF expression in retina of rats with $\mathrm{STZ}$-induced diabetes.

\section{Conflicts of Interest}

The Authors declare no competing interests in regard to this study.

\section{Authors' Contributions}

YHJ and YYC designed the study. RJC and HKS participated in surgical procedures. RJC and HKS analysed the data. HIH performed western analyses. All Authors approved the final article.

\section{Acknowledgements}

This study was supported by research funds from Chosun University (2019).

\section{References}

1 Nazir MA, AlGhamdi L, AlKadi M, AlBeajan N, AlRashoudi L and AlHussan M: The burden of diabetes, its oral complications and their prevention and management. Open Access Maced J Med Sci 6(8): 1545-1553, 2018. PMID: 30159091. DOI: 10.3889/oamjms.2018.294

2 Guo $X$ and Liu X: Nogo receptor knockdown and ciliary neurotrophic factor attenuate diabetic retinopathy in streptozotocin-induced diabetic rats. Mol Med Rep 16(2): 20302036, 2017. PMID: 28656312. DOI: 10.3892/mmr.2017.6850

3 Chen Q, Tan F, Wu Y, Zhuang X, Wu C, Zhou Y, Li Y, Cheng D, Wang J, Lu F and Shen M: Characteristics of retinal structural and microvascular alterations in early type 2 diabetic patients. Invest Ophthalmol Vis Sci 59(5): 2110-2118, 2018. PMID: 29677375. DOI: $10.1167 /$ iovs.17-23193

4 Aldebasi YH, Rahmani AH, Khan AA and Aly SM: The effect of vascular endothelial growth factor in the progression of bladder cancer and diabetic retinopathy. Int J Clin Exp Med 6(4): 239-251, 2013. PMID: 23641300

5 Toraih EA, Abdelghany AA, Abd El Fadeal NM, Al Ageeli E and Fawzy MS: Deciphering the role of circulating lncRNAs: RNCR2, NEAT2, CDKN2B-AS1, and PVT1 and the possible prediction of anti-VEGF treatment outcomes in diabetic retinopathy patients. Graefes Arch Clin Exp Ophthalmol 257(9): 1897-1913, 2019. PMID: 31327036. DOI: 10.1007/s00417-01904409-9

6 Elman MJ, Ayala A, Bressler NM, Browning D, Flaxel CJ, Glassman AR, Jampol LM, Stone TW and Diabetic Retinopathy Clinical Research Network.: Intravitreal Ranibizumab for diabetic macular edema with prompt versus deferred laser treatment: 5-year randomized trial results. Ophthalmology 122(2): 375-381, 2015. PMID: 25439614. DOI: 10.1016/ j.ophtha.2014.08.047

7 Sinclair SH and Schwartz SS: Diabetic Retinopathy-An Underdiagnosed and Undertreated Inflammatory, Neuro-Vascular Complication of Diabetes. Front Endocrinol (Lausanne) 10: 843, 2019. PMID: 31920963. DOI: 10.3389/fendo.2019.00843

8 Sdobnikova SV, Kulybysheva VS. and Sidamonidze AL: [The state of ocular neurosensory apparatus in diabetes mellitus]. Vestn Oftalmol 134(5. Vyp. 2): 263-269, 2018. PMID: 30499527. DOI: 10.17116/oftalma2018134051263

9 Choi MS, Chung YY, Kim DJ, Kim ST and Jun YH: Immunoreactivity of MAPK signaling in a rat model of intrauterine growth retardation induced by uterine artery ligation. In Vivo 34(2): 649-657, 2020. PMID: 32111765. DOI: 10.21873/ invivo.11819

10 Guo W, Nagappan G and Lu B: Differential effects of transient and sustained activation of BDNF-TrkB signaling. Dev Neurobiol 78(7): 647-659, 2018. PMID: 29575722. DOI: 10.1002/dneu.22592

11 Seki M, Nawa H, Fukuchi T, Abe H and Takei N: BDNF is upregulated by postnatal development and visual experience: quantitative and immunohistochemical analyses of BDNF in the rat retina. Invest Ophthalmol Vis Sci 44(7): 3211-3218, 2003. PMID: 12824273. DOI: 10.1167/iovs.02-1089

12 Cusato K, Bosco A, Linden R and Reese BE: Cell death in the inner nuclear layer of the retina is modulated by BDNF. Brain Res Dev Brain Res 139(2): 325-330, 2002. PMID: 12480149. DOI: 10.1016/s0165-3806(02)00570-9 
13 Afarid M, Namvar E and Sanie-Jahromi F: Diabetic retinopathy and BDNF: A review on its molecular basis and clinical applications. j Ophthalmol 2020: 1602739, 2020. PMID: 32509339. DOI: $10.1155 / 2020 / 1602739$

14 Castrén E and Rantamäki T: The role of BDNF and its receptors in depression and antidepressant drug action: Reactivation of developmental plasticity. Dev Neurobiol 70(5): 289-297, 2010 PMID: 20186711. DOI: 10.1002/dneu.20758

15 Livak KJ and Schmittgen TD: Analysis of relative gene expression data using real-time quantitative PCR and the 2(Delta Delta C(T)) method. Methods 25(4): 402-408, 2001 PMID: 11846609. DOI: 10.1006/meth.2001.1262

16 Gong CY, Lu B, Hu QW and Ji LL: Streptozotocin induced diabetic retinopathy in rat and the expression of vascular endothelial growth factor and its receptor. Int J Ophthalmol 6(5): 573-577, 2013. PMID: 24195027. DOI: 10.3980/j.issn.22223959.2013.05.03

17 Addepalli V and Suryavanshi SV: Catechin attenuates diabetic autonomic neuropathy in streptozotocin induced diabetic rats. Biomed Pharmacother 108: 1517-1523, 2018. PMID: 30372853. DOI: 10.1016/j.biopha.2018.09.179

18 Baig MA and Panchal SS: Streptozotocin-induced diabetes mellitus in neonatal rats: An insight into its applications to induce diabetic complications. Curr Diabetes Rev 16(1): 26-39, 2019. PMID: 30973111. DOI: 10.2174/1573399815666190411115829

19 Wang Q, Zhou J, Xiang Z, Tong Q, Pan J, Wan L and Chen J: Anti-diabetic and renoprotective effects of Cassiae Semen extract in the streptozotocin-induced diabetic rats. J Ethnopharmacol 239: 111904, 2019. PMID: 31022564. DOI: 10.1016/j.jep.2019.111904

20 Lee EC, Kim MO, Roh GH and Hong SE: Effects of Exercise on Neuropathy in Streptozotocin-Induced Diabetic Rats. Ann Rehabil Med 41(3): 402-412, 2017. PMID: 28758077. DOI: 10.5535/arm.2017.41.3.402

21 Wang T, Miao M, Bai M, Li Y, Li M, Li C and Xu Y: Effect of sophora japonica total flavonoids on pancreas, kidney tissue morphology of streptozotocin-induced diabetic mice model Saudi J Biol Sci 24(3): 741-747, 2017. PMID: 28386205. DOI: 10.1016/j.sjbs.2017.01.051

22 Kaviarasan K, Jithu M, Arif Mulla M, Sharma T, Sivasankar S, Das UN and Angayarkanni N: Low blood and vitreal BDNF, LXA 4 and altered Th1/Th2 cytokine balance are potential risk factors for diabetic retinopathy. Metabolism 64(9): 958-966, 2015. PMID: 26004392. DOI: 10.1016/j.metabol.2015.04.005

23 Barker PA: Whither proBDNF? Nat Neurosci 12(2): 105-106, 2009. PMID: 19172162. DOI: 10.1038/nn0209-105

24 Jun YH and Kim ST: Brain-derived neurotrophic factor in nonproliferative diabetic retinopathy with diabetic macular edema. Eur J Ophthalmol : 1120672120944801, 2020. PMID: 32686489. DOI: $10.1177 / 1120672120944801$

25 Taşlipinar Uzel AG, UĞurlu N, Toklu Y, Çİçek M, Boral B, Şener B and ÇaĞil N: Relationship between stages of diabetic retinopathy and levels of brain-derived neurotrophic factor in aqueous humor and serum. Retina 40(1): 121-125, 2020. PMID: 30300266. DOI: 10.1097/IAE.0000000000002355

26 Bikbova G, Oshitari T, Baba T and Yamamoto S: Neurotrophic factors for retinal ganglion cell neuropathy - with a special reference to diabetic neuropathy in the retina. Curr Diabetes Rev 10(3): 166-176, 2014. PMID: 24809393. DOI: 10.2174/ 1573399810666140508121927
27 Ola MS and Alhomida AS: Neurodegeneration in diabetic retina and its potential drug targets. Curr Neuropharmacol 12(4): 380386, 2014. PMID: 25342945. DOI: $10.2174 / 1570159 \mathrm{X}$ 12666140619205024

28 Ola MS, Nawaz MI, Khan HA and Alhomida AS: Neurodegeneration and neuroprotection in diabetic retinopathy. Int J Mol Sci 14(2): 2559-2572, 2013. PMID: 23358247. DOI: 10.3390/ijms 14022559

29 Kimura A, Namekata K, Guo X, Harada C and Harada T: Neuroprotection, growth factors and BDNF-TrkB signalling in retinal degeneration. Int J Mol Sci 17(9), 2016. PMID: 27657046. DOI: 10.3390/ijms17091584

30 Behl $\mathrm{T}$ and Kotwani A: Downregulated brain-derived neurotrophic factor-induced oxidative stress in the pathophysiology of diabetic retinopathy. Can J Diabetes 41(2): 241-246, 2017. PMID: 27913110. DOI: 10.1016/j.jcjd. 2016.08.228

31 Price RD, Milne SA, Sharkey J and Matsuoka N: Advances in small molecules promoting neurotrophic function. Pharmacol Ther 115(2): 292-306, 2007. PMID: 17599430. DOI: 10.1016/ j.pharmthera.2007.03.005

32 Huang $\mathrm{H}$, Li H, Shi K, Wang L, Zhang $\mathrm{X}$ and Zhu X: TREK-TRAAK two-pore domain potassium channels protect human retinal pigment epithelium cells from oxidative stress. Int J Mol Med 42(5): 2584-2594, 2018. PMID: 30106090. DOI: 10.3892/ijmm.2018.3813

33 Beshara S, Beston BR, Pinto JG and Murphy KM: Effects of Fluoxetine and Visual Experience on Glutamatergic and GABAergic Synaptic Proteins in Adult Rat Visual Cortex. eNeuro 2(6): ENEURO.0126-15.2015, 2016. PMID: 26730408. DOI: $10.1523 /$ ENEURO.0126-15.2015

34 Ampuero E, Cerda M, Härtel S, Rubio FJ, Massa S, Cubillos P, Abarzúa-Catalán L, Sandoval R, Galaburda AM and Wyneken U: Chronic Fluoxetine Treatment Induces MaturationCompatible Changes in the Dendritic Arbor and in Synaptic Responses in the Auditory Cortex. Front Pharmacol 10: 804, 2019. PMID: 31379577. DOI: 10.3389/fphar.2019.00804

35 Liu X, Zhang J, Sun D, Fan Y, Zhou H and Fu B: Effects of fluoxetine on brain-derived neurotrophic factor serum concentration and cognition in patients with vascular dementia. Clin Interv Aging 9: 411-418, 2014. PMID: 24648723. DOI: 10.2147/CIA.S58830

36 Xie Y, Liu P, Lian Y, Liu H and Kang J: The effect of selective serotonin reuptake inhibitors on cognitive function in patients with Alzheimer's disease and vascular dementia: focusing on fluoxetine with long follow-up periods. Signal Transduction and Targeted Therapy 4(1), 2020. DOI: 10.1038/s41392-019-0064-7

37 Huang J, Liu X, Luo X, Tang C, Xu M, Wood L, Wang Y and Wang QM: Effects of fluoxetine on poststroke dysphagia: A clinical retrospective study. J Stroke Cerebrovasc Dis 27(11): 3320-3327, 2018. PMID: 30174226. DOI: 10.1016/ j.jstrokecerebrovasdis.2018.07.034

$38 \mathrm{Li}$ X, Yao J, Wu J, Du X, Jing W and Liu L: Roles of PRF and IGF-1 in promoting alveolar osteoblast growth and proliferation and molecular mechanism. Int J Clin Exp Pathol 11(7): 32943301, 2018. PMID: 31949704

39 JiaWen W, Hong S, ShengXiang X and Jing L: Depression- and anxiety-like behaviour is related to BDNF/TrkB signalling in a mouse model of psoriasis. Clin Exp Dermatol 43(3): 254-261, 2018. PMID: 29315742. DOI: 10.1111/ced.13378 
40 La Porta CA and Comolli R: PKC-dependent modulation of IkB alpha-NFkB pathway in low metastatic B16F1 murine melanoma cells and in highly metastatic BL6 cells. Anticancer Res 18(4A): 2591-2597, 1998. PMID: 9703914

41 Wu Y, Ma S, Xia Y, Lu Y, Xiao S, Cao Y, Zhuang S, Tan X, Fu Q, Xie L, Li Z and Yuan Z: Loss of GCN5 leads to increased neuronal apoptosis by upregulating E2F1- and Egr-1-dependent BH3-only protein Bim. Cell Death Dis 8(1): e2570, 2017. PMID: 28125090. DOI: $10.1038 /$ cddis.2016.465

42 Valverde AM, Miranda S, García-Ramírez M, GonzálezRodriguez Á, Hernández C and Simó R: Proapoptotic and survival signaling in the neuroretina at early stages of diabetic retinopathy. Mol Vis 19: 47-53, 2013. PMID: 23335850

43 Shin ES, Huang Q, Gurel Z, Palenski TL, Zaitoun I, Sorenson $\mathrm{CM}$ and Sheibani N: STAT1-mediated Bim expression promotes the apoptosis of retinal pericytes under high glucose conditions. Cell Death Dis 5: e986, 2014. PMID: 24407239. DOI: 10.1038/cddis.2013.517

44 Almeida S, Laço M, Cunha-Oliveira T, Oliveira CR and Rego $\mathrm{AC}$ : BDNF regulates BIM expression levels in 3-nitropropionic acid-treated cortical neurons. Neurobiol Dis 35(3): 448-56, 2009 PMID: 19555760. DOI: 10.1016/j.nbd.2009.06.006

45 Yamasaki M, Mishima HK, Yamashita H, Kashiwagi K, Murata $\mathrm{K}$, Minamoto A and Inaba $\mathrm{T}$ : Neuroprotective effects of erythropoietin on glutamate and nitric oxide toxicity in primary cultured retinal ganglion cells. Brain Res 1050(1-2): 15-26, 2005. PMID: 15979589. DOI: 10.1016/j.brainres.2005.05.037
46 Li Z, Zhang J, Liu Z, Woo CW and Thiele CJ: Downregulation of Bim by brain-derived neurotrophic factor activation of TrkB protects neuroblastoma cells from paclitaxel but not etoposide or cisplatin-induced cell death. Cell Death Differ 14(2): 318-326, 2007. PMID: 16778834. DOI: 10.1038/sj.cdd.4401983

47 Scabia G, Barone I, Mainardi M, Ceccarini G, Scali M, Buzzigoli E, Dattilo A, Vitti P, Gastaldelli A, Santini F, Pizzorusso T, Maffei L and Maffei M: The antidepressant fluoxetine acts on energy balance and leptin sensitivity via BDNF. Sci Rep 8(1): 1781, 2018. PMID: 29379096. DOI: 10.1038/s41598-018-19886-x

48 Yang CR, Zhang XY, Liu Y, Du JY, Liang R, Yu M, Zhang FQ, Mu XF, Li F, Zhou L, Zhou FH, Meng FJ, Wang S, Ming D and Zhou XF: Antidepressant drugs correct the imbalance between proBDNF/p75NTR/Sortilin and mature BDNF/TrkB in the brain of mice with chronic stress. Neurotox Res 37(1): 171-182, 2020. PMID: 31493120. DOI: 10.1007/s12640-019-00101-2
Received January 6, 2021

Revised February 4, 2021

Accepted February 5, 2021 